\title{
Examining the willingness, reasons, features and for people to "escape" from Beijing
}

\author{
$\mathrm{Li} \mathrm{LI}^{\mathrm{a}}$, Yuannong CAO, Kui ZOU, Jinfeng JIANG, Shujia LUO
}

Department of Economics and Management, Beijing Information Science \& Technology University, Beijing, 100192, China

aemail: lilinw2001@126.com

Keywords: “escape” from Beijing; Willingness; Features

\begin{abstract}
Based on an investigation analysis, this work examines the willingness, reasons and group features for people to "escape" from Beijing. The results show that, the actual behaviors for people to "escape" from Beijing are not as popular as its voice, only a few percentage of the population really want to leave Beijing. The main reasons driving those people to leave are identified the bad air quality, high housing price and traffic congestion and high working prressure. Most of them want to move to other developed regions. Those people who planned to or want to leave Beijing is characterized by middle level educated, younger age, freer job transformation, longer living in Beijing, being born in other places except Beijing, without hukou and relative higher house living densities. This may imply the transformation of Beijing's economic function to more politics intensive aspects.
\end{abstract}

\section{Introduction}

Urbanization, which is the necessity and outcome of economic and industrial development, causes huge migration of population to metropolis. Beijing, the capital of China, began its large scale urbanization process since 80s of last century and by the end of 2014, over 21.516 million residents lived in Beijing, of which over 8 million were floating residents. Such a huge amount of population had caused many serious problems covering all aspects, like traffic congestion, energy security, resources' shortage and environment pollution for Beijing. As a result, the Beijing government planned to control the growth of population by all kinds of policies, the effects of these policies is very hard to measure. And also because of the ever increasing costs of living Beijing, deterioration of environment, there is a popular voice among the society that is to "escape" from Beijing now. However, because the reasons for people choose to escape from Beijing are different and vary, it is very important for the government to know what are the most important reasons for people to migrate again.

Topics of population concentration and diffusion were popular for several years [1-3], and recent years because of the ever increasingly fast speed of China's urbanization, the researches on China's population migration are also increasing. For example, Yin [4] gives an insightful retrospect and prospect of Chinese migration and urbanization process, and $\mathrm{Yu}$ [5]'s research shows that the eastern region of China attracts floating population because of its modernization, internationality and higher living quality. Because the population problems are so special in Beijing, it is very necessary for researches to select the city of Beijing as a single problem to study, and this can be seen in [6-11]. For most of these researches, there was a not very important factor in the past but now is an important factor that influences population migration, which is air pollution, neglected. So in this work we developed an interview-based research to examine the effects of air pollution on population diffusion in Beijing. A questionnaire was designed to test people's willingness to leave Beijing and also the features of the population who want to leave was identified, the result is very useful for Beijing government to plan its population control policies.

The following parts of this work were constructed as: Part 2 introduces the questionnaire; Part 3 brings out the main findings of the questionnaire including the reasons for people to leave Beijing, the features of the people who want to leave and so on; Part 4 concludes the work and provide a 
deep insight for future population policies in Beijing.

\section{Summary of the Questionnaire}

The questionnaire contains 16 questions, which can be divided into two groups focusing on: 1) the background of the respondents; 2) the escaping willingness of the respondents. Totally 803 questionnaires were received and 751 of them were proved to be effective after rigorous test and selection. All of these questionnaires are collected by personal interview and then the data was entered into an internet-based questionnaire analyzing system for statistical calculation.

\section{Main Results}

1. Willingness to "escape” from Beijing

We developed a question on "would you want to escape Beijing” to test the population's willingness to leave Beijing. The results show that $48.93 \%$ of the respondents never considered about this problem, and $41.07 \%$ of the respondents just thought about it and they didn't have a plan about it, only $10 \%$ of the respondents showed that they were really carefully planned it and the "escaping" plan will be implemented in the future. This finding show that although there is a voice that it is time for people to escape from "Beijing", but actually only a small proportion of them really want to do that, most of the people are still waiting for the future signs, the willingness to "escape" from Beijing now is not as popular as the voice.

For those people who had planned or think about "escaping” from Beijing, $41 \%$ of them said they will or may leave Beijing in 3-5 years later, and 20\% of them said they will or may leave Beijing in less than 2 years or 5-10 years later, still there are $19 \%$ of them said they will leave Beijing in more than 10 years later. The statistics show that "escaping" from Beijing is not a very easy thing for most of the people to decide.

Also on the places they want to "escape" to, $40 \%$ of the respondents showed that they want to go back to home, only $16 \%$ of them want to go to other first line cities in China like Shanghai, Guangzhou and so on. There are still $24 \%$ of the respondents showed that they want to go to the second or third line cities. Also there are about $10 \%$ of the respondents planned to go abroad. Only a small proportion of the respondents showed they are willing to go to counties or other places. For those people who want to go back to their home, $54.55 \%$ of their homes are much more or very developed. So it can be foreseen that when most of the people who planned to escape from Beijing really escape, they will go to other more developed regions in China.

2. Reasons for people to "escape" from Beijing

Generally speaking, for those who plan to or consider to "escape" from Beijing, the reasons varied a lot, and among all the reasons, the statistical results show that the bad air quality, high estate price, traffic congestion and high pressure in works in Beijing are the most important factors (Fig. 1). These four factors are the most important issues determining the living quality of a family. So it can be concluded the factors that cause the increase in living costs, traffic inconvenience and environmental issues threatening the health are the main driving forces for people to migrate again, while the effects of Hukou policy which the government used to use for controlling population growth in Beijing is so limitless comparing to the effects of the above 4 factors. Also this findings show that, population migration again from Beijing is more like a self-selection process for most of the people.

3. The features of people who want to "escape" from Beijing

(1) Gender

Among the people who had considered or planned to escape from Beijing, 51.30\% of them are male and $48.69 \%$ of them are female, there is a very little difference among them, and it can be concluded actually, the willingness of "escaping” from Beijing is irrelative to gender.

(2) Educational background

The Educational backgrounds vary a lot among the people who want to "escape" from Beijing, generally speaking (Fig.2(a)), lots of people with undergraduate degrees want to "escape" from 
Beijing, and the ones with very higher eduction backgroud like master or above, the possbilities for them to leave is much small, the same as the ones with lower eduction backgroud. Which means the current living in Beijing is quite tough for the middle level educated people.
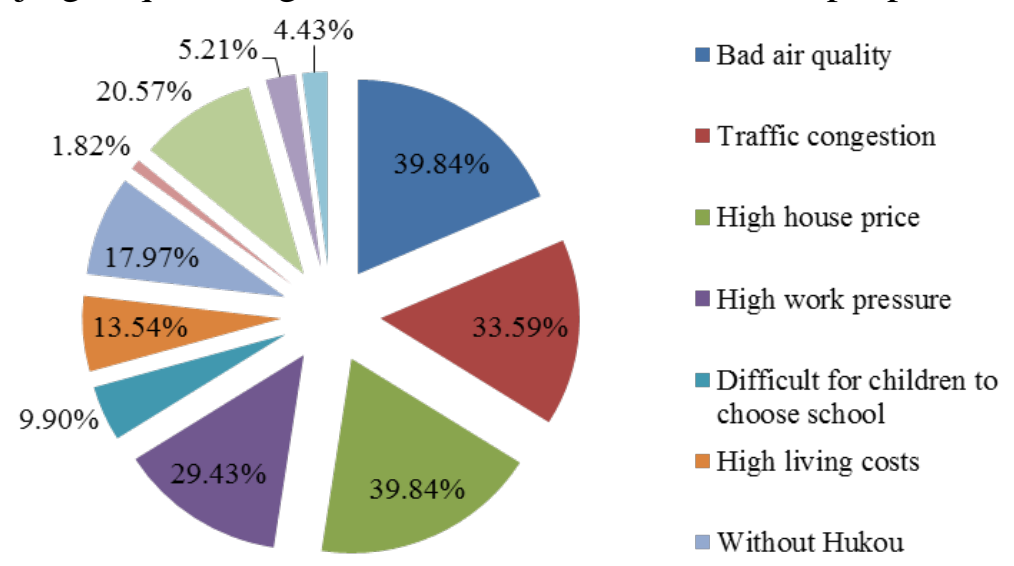

Figure 1 Reasons for people to “escape” from Beijing

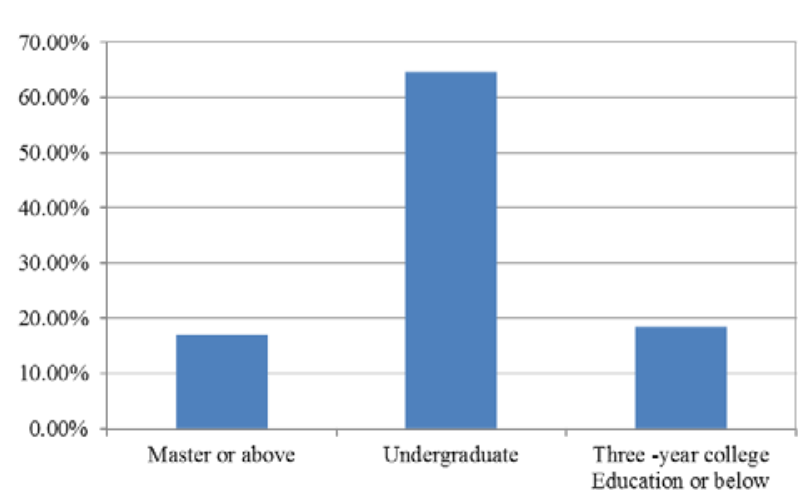

(a) Education Background

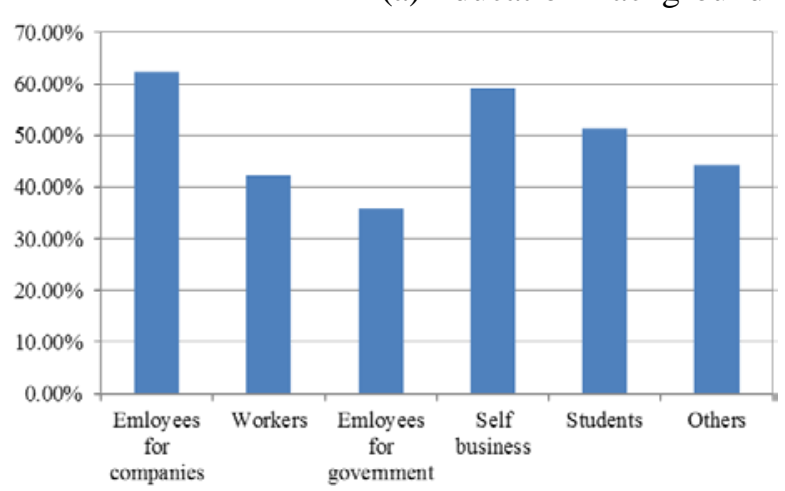

(c) Occupation

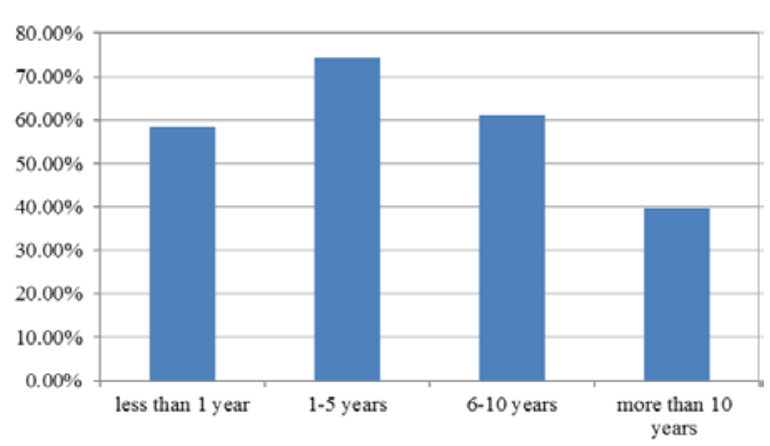

(e) Years being in Beijing

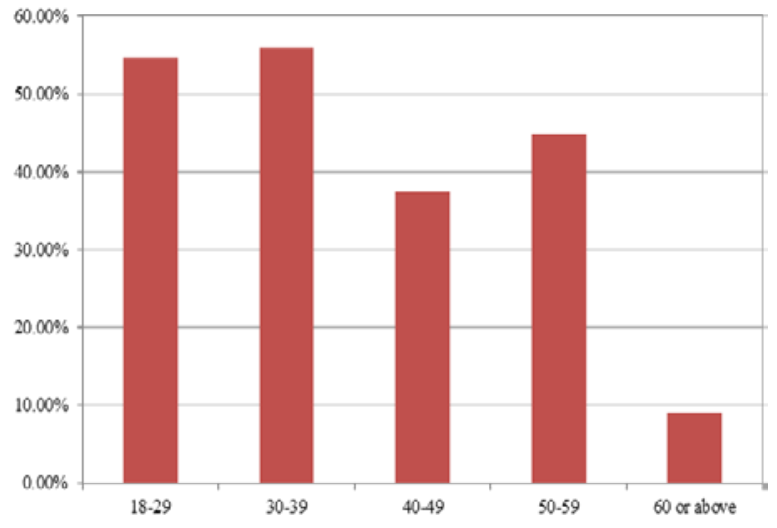

(b) Age

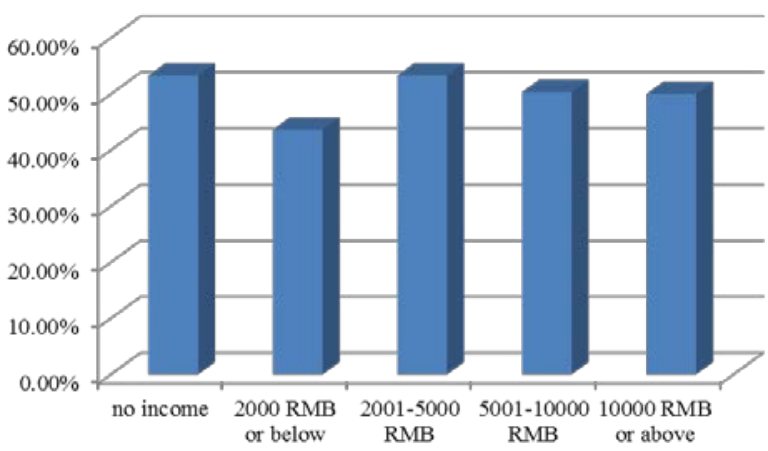

(d)Income

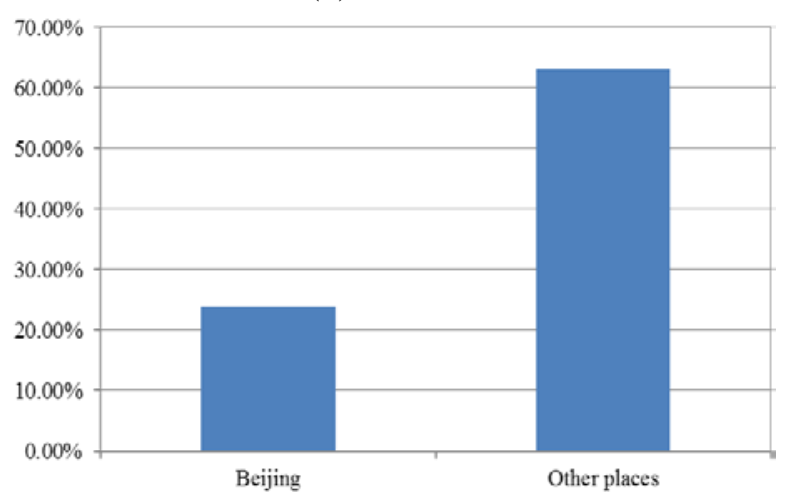

(f)Hometown 


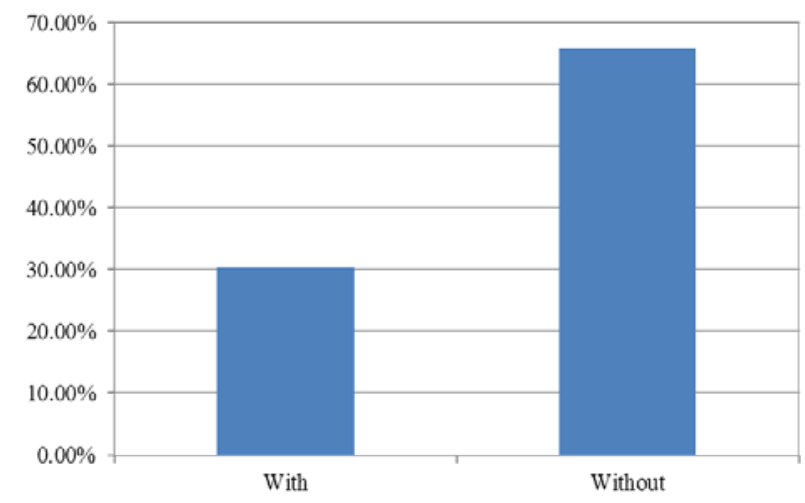

(g) Hukou

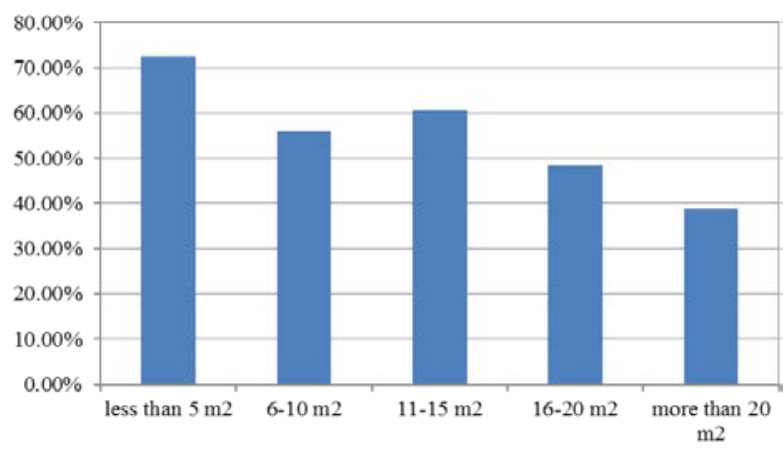

(h)House density ( $\mathrm{m}^{2} /$ population)

Figure 2 Proportion of people who want to "escape” from Beijing in regarding to different features

(3) Age

Among all the respondents who are willing to or considering to leave Beijing, we found that most of them are among the 18-29 or 30-39 years. As Fig.2 (b) shows, more than $50 \%$ of the people among 18-29 or 30-39 years expressed that they had planned or considered to leave Beijing, while among the years of $40-49$ and $50-59$, the proportion dropped to around $40 \%$, for people who were 60 years old or above, no more than $10 \%$ of them will leave Beijing. These findings prove that on the one hand the current livings in Beijing is more tough for the youth, and on the other hand, on the long run the aging problem will be even more serious and also the population will decrease because of the shortage of youth age.

(4) Occupation

Among the people who plan or consider to leave Beijing, about $60 \%$ of the employees from companies or self-business are ever considered or planned this problems, coupled with $50 \%$ of the students (Fig.2 (c)). While the employees show the lowest willingness to leave Beijing, most of the workers also show lower willingness to leave. This implies that the current circumstances may more suitable for people neither have highest stable jobs or lowest jobs to live, the uncertainties of future make those people who want a better life to consider where they can get better requirements for their livings. So it can be foreseen that if current working situations continues, the economic center position of Beijing should be changed, and the politics position should be enforced.

(5) Income

In regarding to the income level of the respondents who are willing to or considering to leave Beijing, the results show that there is not too much difference among the ones who have no income, or earn about 2001-5000, 5001-10000 and 10000 or above RMB each month, the willingness of the ones who earn less than 2000 RMB is slightly lower than other groups (Fig.2 (b)), however the gaps are not so much obvious, so it can be concluded that the income is not an obvious factor that influencing people’ willingness to “escape” Beijing.

(6) Years Being in Beijing

As Fig.2 (e) shows, generally speaking, for people who have leaving in Beijing for more than 1 years and less than 10 years, the willingness to leave Beijing is higher than other two groups, and except who are in Beijing for less for 1 years, the willingness to leave Beijing decrease with the increase of years people had lived in Beijing. So it can be seen that the future population migration mainly will emerge among people who had migrated to Beijing for short time.

(7) Hometown

As Fig.2 (f) shows, for people who was born in Beijing, the willingness to leave Beijing is rather low than the ones who were not born in Beijing. This findings show that the current living situation will make more foreign migrators to migrate again, which will further enhance the strengths of native people in Beijing.

(8) Hukou

As Fig.2 (g) shows, it is obvious that people who already got a hukou from the government, the willingness to leave Beijing are rather lower than the ones who did not get a hukou. Although without hukou is not the most important reason for people to leave Beijing, with hukou is the an 
important reason for people to stay in Beijing.

(9) House density

Because the difficulties to buying a house in Beijing is one of the most important factors driving people to leave Beijing, so people who with lower house living standard is supposed to be more willing to leave Beijing. The results are slightly different with the assumption, as the one whose house average living room was $11-15 \mathrm{~m}^{2}$ each person are more willing to leave Beijing than the one whose with 6-10 $\mathrm{m}^{2}$ each person (Fig.2 (h)), however, the overall trend in Fig.2 (h) shows that the larger the room for each person in their house, the lower the willingness to leave Beijing.

\section{Conclusion}

This work examines the willingness, reasons and group features for people to "escape" from Beijing, the results imply that the current population migration more likes a people' self-selection process, the current living situation is rather tough for the youth people who was middle-level educated, with relatively lower income and housing living standard, which means that Beijing may have a shortage of middle-level labors in future, which will further weaken the economics function of Beijing, and reinforce its political function.

\section{Acknowledgement}

The research was sponsored by National Natural Science Foundation of China (Project No.71403030) and Beijing Philosophy and Social Science Fund (13JGC074、14JGC108).

\section{References}

[1] Feng Jian, Zhou Yixing. Recent 20 years' population growth and distribution in urban areas of Beijing [J]. Acta Geographica Sinica, 200358 (6) 903-916

[2] Small K A, Song S. Population and employment densities: Structure and Change [J]. Journal of Urban Economics, 1996 (36): 292-313

[3] Mc Donald J, Prather P. Subruban employment centers: the case of Chicago [J]. Urban Studies, 1994 (31) 201-218

[4] Yin Jiangbin, Li Xun. Retrospect and Prospect of Chinese migration and urbanization process [J], Urban Problems, 2012 (12) 23-29

[5] Yu Taofang. Spatial-temporal Features and Influential Factors of the China Urban Floating Population Growth [J], Chinese Journal of Population Science, 2012 (4) 47-59

[6] Liu Changan. A comparative study of population migration and international migration in metropolis [J], Labor and social security in the world (Theory), 2013 (1) 108-112

[7] Yu Taofang. A scenario analysis on the population growth trend in Beijing and Tianjin corridor space: Concentration and Diffusion, Perspective, Beijing Planning Review, 2012 (4): 13-19

[8] Ye Limei. The reasons for the population pressure in Beijing and the methods to relieve it [J], Beijing Planning Review, 2010 (3) 105-107

[9] Feng Zhiming, Yang Ling, Yang Yanzhao and You Zhen. The process of population agglomeration/shrinking and changes in spatial pattern in the beijing-tianjin-hebei metrolitan region [J], Journal of Geo-information Science 201315 (1) 11-19

[10] Guo Min, Rao Ye, Yu Wei, Song Jinping. New features and implications for the population spatial development in Beijing metropolitan area [J], Urban Development Studies 2013 (6) 110-115

[11] Liang Haoguang, Liu Yansui. Study on spatio-temporal change and simulation of population in Beijing based on census data [J], Acta Geographica Sinica 201269 (10): 1487-1495 